\title{
TV/Series
}

$10 \mid 2016$

Guerres en séries (II)

\section{Le fracas silencieux de la guerre dans The X-Files (1993-2002; 2016)}

Frédéric Gai

\section{(2) OpenEdition}

Journals

Édition électronique

URL : http://journals.openedition.org/tvseries/1887

DOI : 10.4000/tvseries.1887

ISSN : 2266-0909

Éditeur

GRIC - Groupe de recherche Identités et Cultures

Référence électronique

Frédéric Gai, « Le fracas silencieux de la guerre dans The X-Files (1993-2002; 2016) », TV/Series [En ligne], 10 | 2016, mis en ligne le 01 décembre 2016, consulté le 20 avril 2019. URL : http:// journals.openedition.org/tvseries/1887; DOI : 10.4000/tvseries.1887

Ce document a été généré automatiquement le 20 avril 2019

\section{(c) (i) (2) $\Theta$}

TV/Series est mis à disposition selon les termes de la licence Creative Commons Attribution - Pas d'Utilisation Commerciale - Pas de Modification 4.0 International. 


\title{
Le fracas silencieux de la guerre dans The X-Files (1993-2002 ; 2016)
}

\author{
Frédéric Gai
}

The X-Files a repris en janvier 2016 pour une dixième saison, plus de treize ans après la diffusion de "The Truth» (9.19-20), double épisode concluant la neuvième et, initialement, dernière année de production du show créé par Chris Carter. En 2002, cette fin, réalisée sur fond de bilan et de relance, se fait dans le cadre d'une critique frontale des structures dirigeantes de l'armée américaine. Mulder (David Duchovny) réussit en effet à s'introduire dans la base de Mount Weather afin de consulter des documents classifiés, en l'occurrence ceux annonçant l'invasion finale des extraterrestres pour le 21 décembre 2012. Poursuivi par Knowle Rohrer (Adam Baldwin), un super-soldat / extraterrestre figure de la dernière mutation du complot (fig.1), l'agent du FBI le fait basculer par-dessus une balustrade. 
Figure 1 : Le super-soldat Knowle Rohrer dans « The Truth ».

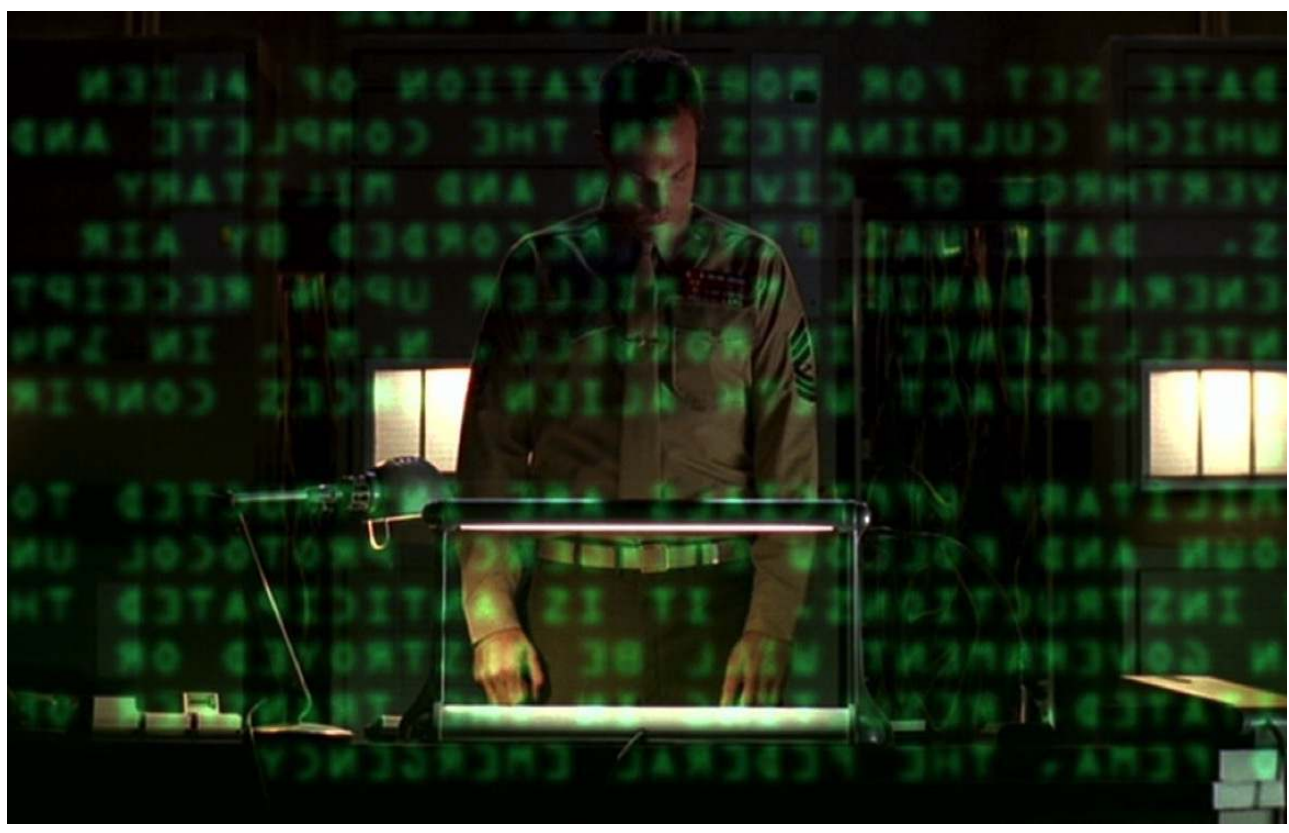

Il est alors jugé par un tribunal militaire pour le meurtre d'un être pourtant indestructible et condamné à mort au terme d'un simulacre de procès où les hiérarchies militaires et policières ne sont pas en mesure d'admettre la vérité... Mulder s'évade finalement et, accompagné de Scully (Gillian Anderson), part en cavale au NouveauMexique où il croise une dernière fois (croit-il) la route de l'Homme à la cigarette (Michael B. Davis).

2 Treize années ont passé, donc. Treize ans entrecoupés d'une enquête sur grand écran à propos d'un trafic d'organes, sur fond de religion et de manipulation génétique ${ }^{1}$. Le spectateur a retrouvé Mulder et Scully, entre changement (ils sont séparés, ils ne travaillent plus pour le FBI) et immuabilité (Mulder est toujours prompt à suivre les théories du complots, même les plus fumeuses de prime abord). Si la minisérie ${ }^{2}$ s'inscrit $^{\prime}$ bien dans la continuité diégétique, narrative et esthétique des saisons précédentes, il faut noter l'abandon du sujet guerrier lors des six épisodes diffusés, et ce bien que les quelques exceptions soient tout à fait significatives de la position d'X-Files par rapport à l'histoire de son propre discours, mais aussi au cadre contemporain des États-Unis.

Nous pourrions expliquer cette absence par une raison simple, à savoir le format resserré de la saison 10 comparé à la vingtaine d'épisodes annuels marquant la production dans les années 90. Il était alors possible aux créateurs d'instaurer un rythme plus lent et, surtout, de traiter de la pluralité des sujets caractérisant la société américaine de son temps. Les impacts de la Seconde Guerre mondiale, des conflits au Vietnam ou en Irak côtoient alors des récits centrés sur le chômage, l'immigration, les sectes ou encore l'écologie.

$4 \quad X$-Files est marqué par son époque et encadré par deux événements historiques majeurs. Le début des années 90 est fortement influencé par la chute du bloc de l'Est et la fin de la guerre froide. Un nouvel ordre mondial s'annonce. Les États-Unis s'engagent rapidement contre Saddam Hussein, dans un conflit limité permettant principalement, selon les propos de Michael Kritschgau (John Finn) dans «Redux I» (5.1), d'entretenir la dynamique économique militaro-industrielle. À ce sujet aussi continuité et changement 
font bon ménage : si la bactérie s'est substituée à l'atome, la volonté serait de maintenir un état guerrier permanent.

5 À l'autre bout de la première chronologie x-filienne, se trouvent les attentats du 11 septembre. S'il est difficile de juger à quel point ces événements ont marqué la série, dont la neuvième saison est diffusée à partir du 11 novembre 2001, quelques images fortes de son univers semblent les annoncer ${ }^{3}$. Au cœur de cette décennie, The X-Files n'aura eu de cesse de jouer avec l'image d'un pays ayant dorénavant le monopole des superpuissances, notamment pour écorner la croyance en ses facultés à sauver le monde et installer l'idée que les États-Unis servent avant tout leurs intérêts impérialistes.

6 Deux images, empruntées aux premier et dernier épisodes de la dixième saison (soit ceux de son arc mythologique), illustrent toutefois la position double de la série, si ce n'est à l'égard de la guerre, mais plus largement de l'armée. Dans « My struggle I» (10.1), Mulder découvre grâce à l'intervention de Tad O'Malley (Joel McHale) un entrepôt secret où le professeur Garner (Hiro Kanagawa) a réussi à recréer de toutes pièces un vaisseau extraterrestre capable de voler grâce à l'énergie libre. Des hommes armés, qui renvoient à l'image de forces spéciales ou de milices, viennent alors détruire l'engin (fig. 2). Ces soldats représentent l'action rapide, silencieuse et sans visage. Ils répondent sans contestation aux décisions iniques d'une administration corrompue désireuse de cacher ses exactions.

Figure 2 : La milice noire et anonyme de « My struggle I ».

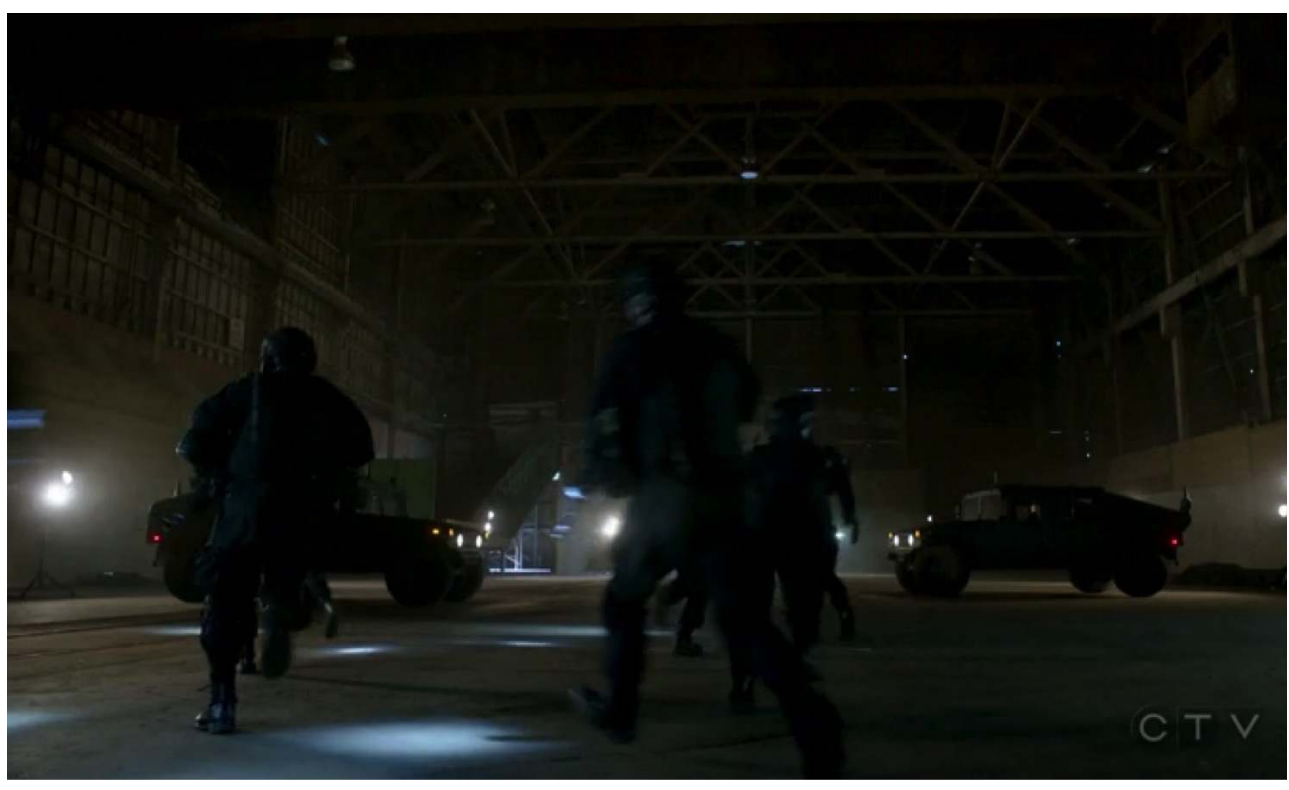

7 Dans «My Stuggle II» (10.6), c'est Scully qui croise la route de militaires, cette fois victimes de l'attaque bactériologique à grande échelle qui vient de se déclencher. Ces hommes, dont nous voyons cette fois le visage, constituent les premières victimes de l'activation de leur vaccin contre l'anthrax (fig. 3). 
Figure 3 : Le soldat, première victime de l'invasion bactériologique.

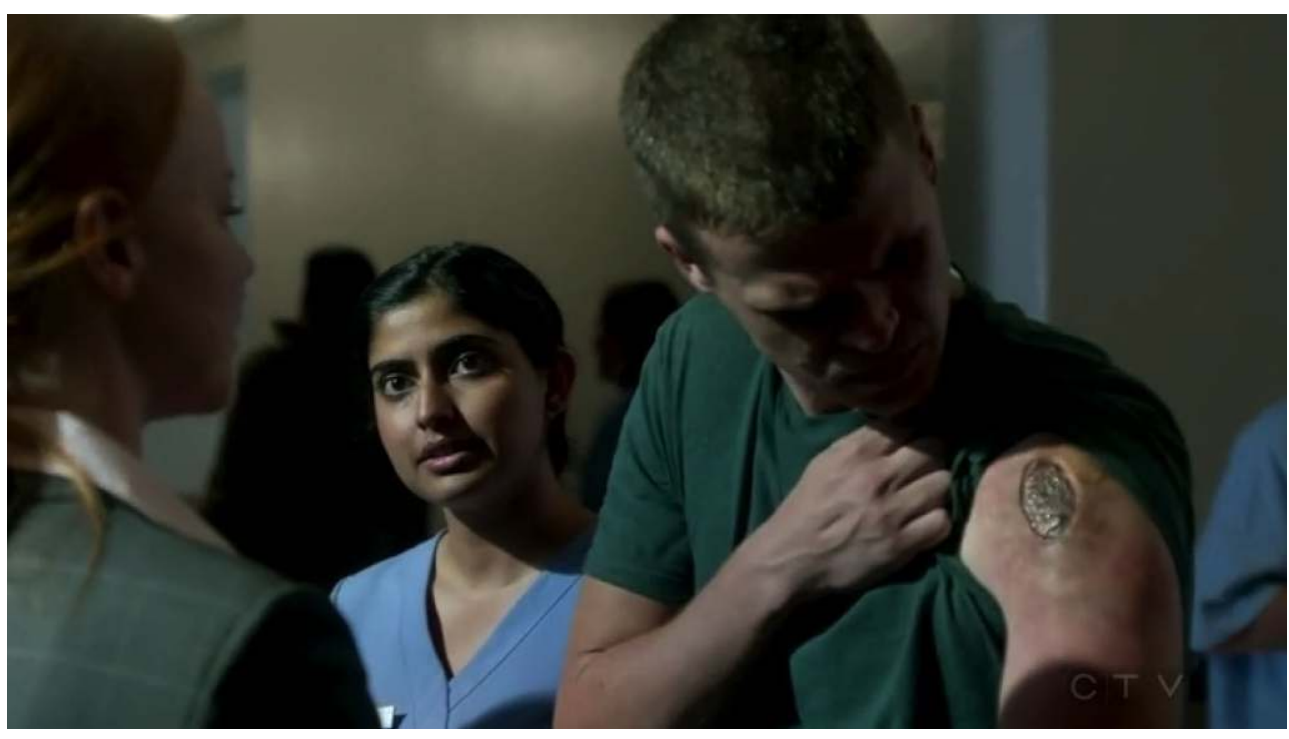

Cette image ambivalente du soldat et le jeu des responsabilités qu'elle révèle traverse l'intégralité de la série. Au-delà même de créer une répartition dialectique entre les coupables et les victimes, la série tend à exposer les deux faces d'un problème et, surtout, à mettre en scène la persistance d'une situation de conflit dans la société américaine, en installant dans son cadre fictionnel un discours réaliste et en utilisant bon nombre de références culturelles, qu'elle valide ou rejette. La traversée des conflits, qu'ils appartiennent à l'Histoire, résonnent encore dans le présent ou fassent partie du réel contemporain, participe de la quête de transparence des deux agents, où la réalité sensible s'oppose finalement aux forces occultes et guerrières.

\section{L'ancien combattant, révélateur de la guerre dans The X-Files}

8 S'inscrivant dans une longue tradition cinématographique à laquelle la série ne cesse de faire référence, The X-Files laisse une place relativement importante aux guerres du passé et du présent. Toutefois, les images d'archives sont rares et la production prend toujours le parti d'évoquer les affres historiques par le filtre du souvenir. En somme, l'ancien combattant, qu'il soit érigé en héros de guerre ou présenté comme une de ses victimes, constitue le mémorial le plus tangible et de plus vif de l'histoire militaire américaine. À ce titre, les différents épisodes traitant des conflits au Vietnam ou dans le Golfe posent toujours en des termes problématiques la frontière entre le héros et la victime, entre la victoire, guerrière et idéologique, et la défaite, contestant les discours officiels et les jeux de la communication.

\section{La face cachée du héros national}

La force d'apparat est l'un des premiers sujets de la série. Dans «Deep Throat» (1.2), épisode aux orientations post-Watergate, la série fait sienne la question de la course à l'armement militaire. La bataille technologique qui fait rage dans le silence des bases armées secrètes, avec toujours en toile de fond les évènements de la guerre du Golfe, est 
une épreuve bien trop dure, même pour les soldats les plus aguerris. L'épisode s'ouvre sur une scène d'intervention d'une unité d'élite dans une résidence militaire où le colonel Robert Budahas (Andrew Johnston) est prostré, visiblement brûlé et sous le choc. Si le personnage déclencheur de l'action narrative est progressivement délaissé, c'est pour mieux souligner à quel point le soldat est soumis à une pression telle qu'elle est difficile à décrire et que l'institution militaire, ici l'archétype de la "grande muette", cherche à passer sous silence. Le pilote de supersoniques est pourtant un soldat dont les actions ont été couronnées de succès et dont la bravoure et le courage sont reconnus jusque dans les plus hautes sphères de l'État. Dans l'intimité, le militaire devient alors un héros déchu (fig. 4).

Figure 4 : Les deux visages du colonel Robert Budahas.

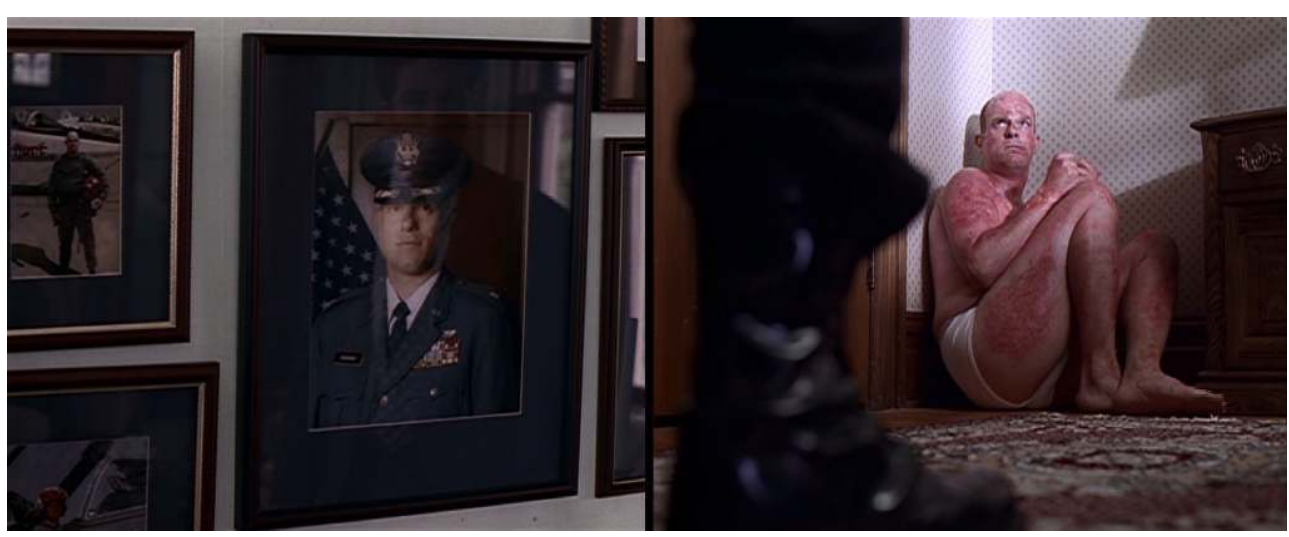

10 Cette figure du héros et de la face «cachée » de la guerre est bien le sujet central de «Unrequited» (4.16), épisode particulièrement chargé symboliquement. La mise en scène adopte très régulièrement des plans avec le drapeau américain et le moment central de l'épisode se déroule au mémorial des anciens combattants. Il est significatif que la scène d'ouverture, au cours de laquelle Mulder et Scully tentent de protéger le général Benjamin Bloch (Scott Hylands) du tueur invisible qu'est le sergent Nathaniel Teager (Peter LaCroix), soit reprise à la fin de l'épisode. Se déroulant au National Mall, elle permet d'insister sur la fonction mémorielle du récit et sur la fragilité des discours officiels. L'armée appuie l'idée selon laquelle l'Amérique serait sortie, si ce n'est victorieuse, mais tout au moins grandie du conflit asiatique. En somme, cette démarche d'héroïsation montre à quel point, comme l'explique Benjamin Stora, "l'Amérique a transformé son passé vietnamien en légende et, en dépit de tous les crimes, tente de se rêver innocente ${ }^{4}$ ».

11 Teager aurait ainsi été, comme d'autres soldats dont il possède la liste, laissé pour mort au Vietnam et vient aujourd'hui hanter les responsables de son désarroi. S'inscrivant évidemment dans la tradition du cinéma américain sur le Vietnam, l'épisode fait écho à plusieurs références. D'un côté, nous retrouvons des productions telles que Missing in action (Joseph Zito, 1984) ${ }^{5}$ qui ont largement mis en scène le récit complotiste de soldats abandonnés sur place ${ }^{6}$. De l'autre, il laisse une réelle place au "retour» des anciens combattants, à ses remords, à sa difficulté de réinsertion et, éventuellement, à sa folie traumatique. Nous nous situons alors dans la continuité des Visiteurs (Elia Kazan, 1972), de Taxi Driver (Martin Scorcese, 1976) ou de Rambo (Ted Kotcheff, 1982). En adoptant une position médiane, la série tente d'ouvrir une voie critique et de confondre les coupables. Taeger s'en prend à Bloch et à d'autres hauts-gradés, mais il ne s'attaque pas réellement à 
son pays, répétant son identité et son numéro de matricule jusqu'à son dernier souffle : il est tout sauf un déserteur (fig. 5). Il fait office de révélateur, "comme si, affirme Benjamin Stora, le registre guerrier ne pouvait être que celui du désenchantement, pas celui d'une rupture avec sa nation livrant une sale guerre ${ }^{7} »$.

Figure 5 : le sergent Nathaniel Teager, mort sous les drapeaux.

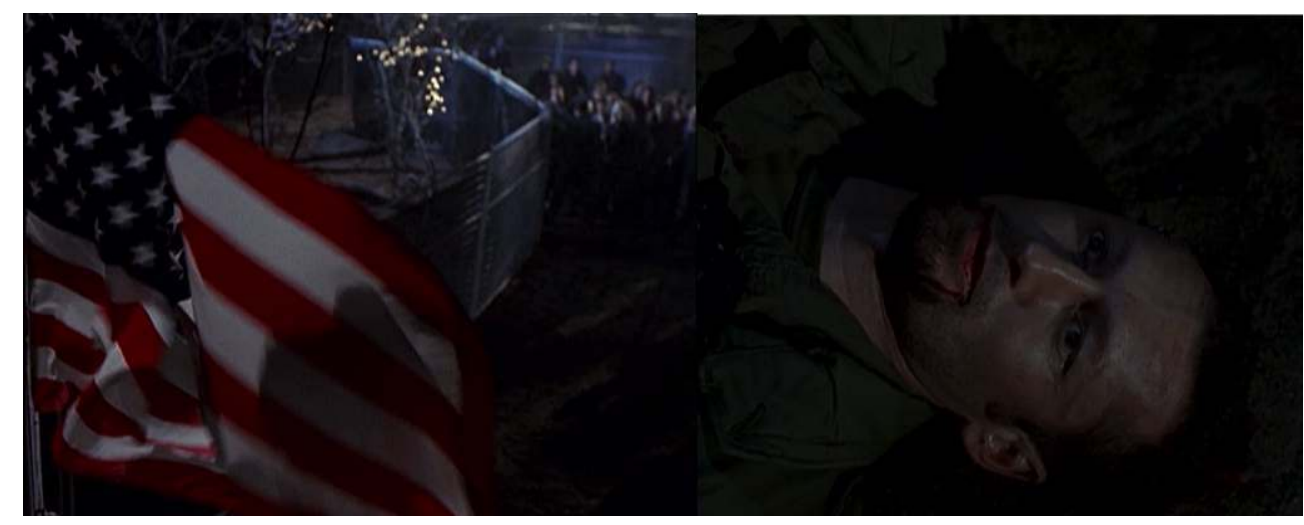

\subsection{Pénétrer l'irréel}

12 À chaque fois qu'un ancien combattant est mis en scène, la série adopte un angle sociopsychologique. L'idée est bien, dans un premier temps, de donner la parole aux oubliés de la guerre, à des soldats mis au ban de la société, laissés pour compte et rongés par de sombres souvenirs. Telle est, par exemple, la situation de Henry Willig (Don Thompson), comme il l'expose à son ancien compagnon d'arme Augustus Cole dans «Sleepless» (2.4) :

How I am doing ? I'm, uh, trying to forget. You know ? I'm trying to get it out of my head. [...] No, I'm, uh, still fighting it, you know. I keep seeing the faces. Every day I see...

Dans cet épisode, Cole est un ancien marine qui a appartenu à une unité d'élite opérant au Vietnam ${ }^{8}$. Chaque soldat y étant incorporé a subi une opération chirurgicale pour ne plus dormir et ainsi vaincre l'ennemi sur ces faiblesses «naturelles». Le silence qui entoure ces opérations militaires n'est pas l'unique facteur de l'émergence du phénomène paranormal (le premier étant une mort par immolation... sans aucune trace d'incendie) : c'est bien l'incapacité des anciens combattants à trouver le repos et l'oubli, mais aussi leur compréhensible propension à revivre le conflit, qui fait figure d'événement anormal. L'horreur que ces soldats ont perpétrée revient les hanter et se transforme en phénomène violent pour une société touchée par l'ignorance.

En liant ces deux aspects du discours de l'épisode, The X-Files considère la guerre du Vietnam avant tout comme un traumatisme. L'oubli et la stabilité sont uniquement de façade et le conflit, ses images violentes et ses douleurs associées, constituent l'un des talons d'Achille, l'une des failles de la société américaine. Par l'entremise du phénomène paranormal, The X-Files pénètre dans la fumée hallucinogène, pour ne pas dire hallucinatoire, de la guerre. Le vétéran est mis à nu. Son innocence est mise à mal. En somme, c'est le meilleur de l'Amérique, de ses hommes et de ses mythes, qui meurt dans le conflit. Cet épisode, s'il porte une force critique indéniable, notamment en vu de rétablir une vérité, s'inscrit aussi dans une longue tradition culturelle. La horde sauvage 
qui vient hanter Willig (fig. 6) est un écho à Full Metal Jacket (Stanly Kubrick, 1987) et l'épisode, à la fois sombre et baroque, pourrait s'inscrire dans la continuité d'une oeuvre telle qu'Apocalypse now (Francis Ford Coppola, 1979).

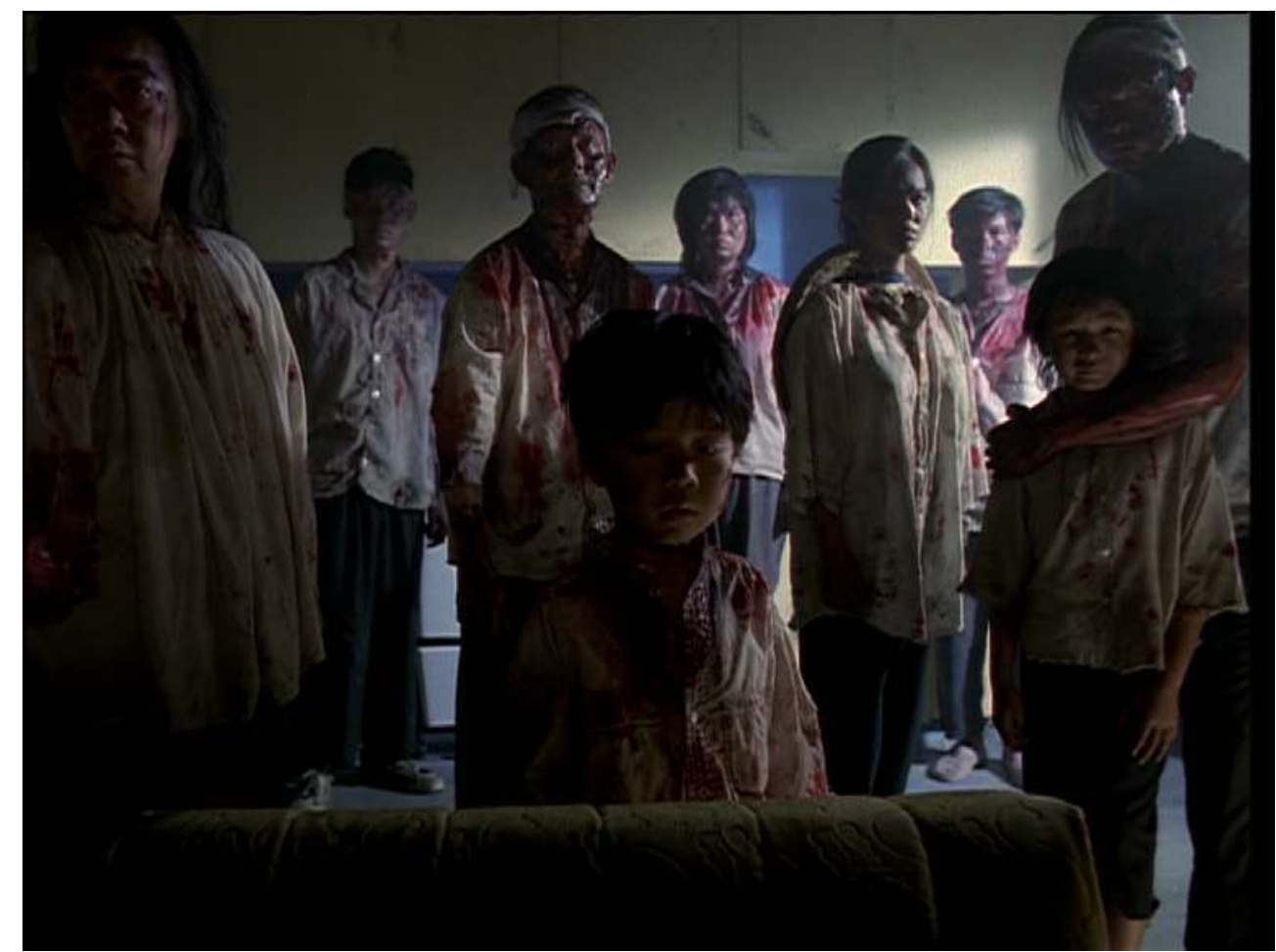

Figure 6 : La « horde sauvage » apparaissant devant Henry Willig (2.4)

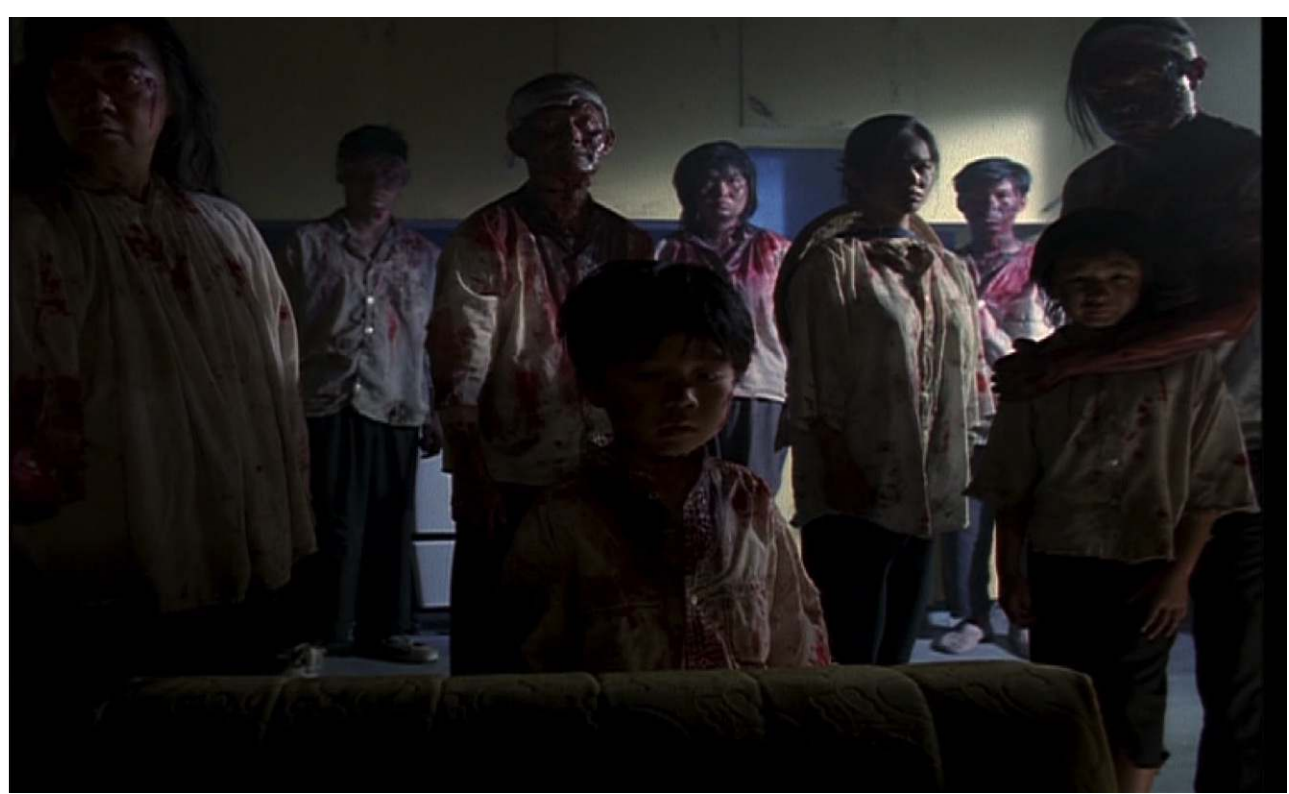

Il vient ainsi inscrire la guerre du Vietnam dans le cadre d'un conflit médiatisé9. Le soldat pénètre dans un univers irréel et participe à l'édification, en même temps qu'il subit, un nouvel imaginaire de guerre.

La guerre du Vietnam accélère la construction d'un imaginaire de guerre, en fuite dans l'irréel. L'omniprésence des images télévisées du conflit crée l'illusion, à la fois d'un «partage démocratique » du malheur et d'un 
consensus idéologique sur les valeurs d'une démocratie à défendre contre un « ennemi invisible ». Nous entrons dans une autre représentation du monde de la guerre, dématérialisée. ${ }^{10}$

The X-Files tente alors de retourner la communication officielle et sa dérive sémiologique, notamment en essayant de voir au-delà du matraquage médiatique. À la suite de la force des images, la série dénonce, en quelque sorte, le fracas du silence.

\subsection{Le vétéran et la forme itérative du conflit}

Le retour de l'ancien combattant, blessé et traumatisé, la force médiatique et son impact sur les productions cinématographiques, les questions de la victoire, des mythes et de l'innocence perdue sont autant de sujets esthétiques et narratifs découlant directement de la guerre du Vietnam. À ce titre, il paraît essentiel de souligner une réelle continuité (pour ne pas dire une vraie gémellité), opérée par The X-Files, dans le traitement de la guerre du Golfe. Bien évidemment, des spécificités sont intégrées, notamment concernant le syndrome de la guerre du Golfe qui toucherait Franck «Ranheim» Druce (Peter LaCroix ${ }^{11}$ ) dans E.B.E. (1.17) ou le fils de Michael Kritschgau (5.2), alimentant une dénonciation de l'ère biologique qui oriente tout une partie de la série. Toutefois, Langly (un des trois Lone Gunmen) considère que ce mal peut être considéré comme l'agent orange des années 90 , traçant déjà une continuité entre les deux conflits. C'est une nouvelle fois l'ancien combattant qui permet de mettre en scène une forme réitérée de conflit et de traumatisme.

17 En effet, un épisode tel que "The Walk" (3.7) fonctionne de la même manière que «Sleepless» (2.4) ou «Unrequited» (4.16). Le lieutenant colonel Victor Stans (Don Thompson) réchappe pour la troisième fois à une tentative de suicide. Alors qu'il est admis dans le service de grands brûlés de l'hôpital de Fort Evantson, il explique qu'une force obscure l'empêche de mettre fin à ses jours. Le silence sembler opérer autour du général Thomas Callahan (Thomas Kopache) et des secrets sur la guerre en Irak. Dans ce cas, Leonard Trimble (Ian Tracey), capable dans un état de transe de mettre en action un " corps astral ${ }^{12}$ ", s'attaque aux familles de Stans et de Callahan afin de se venger (fig. 7).

Figure 7 : Les deux corps de Leonard Trimble (« The Walk »)

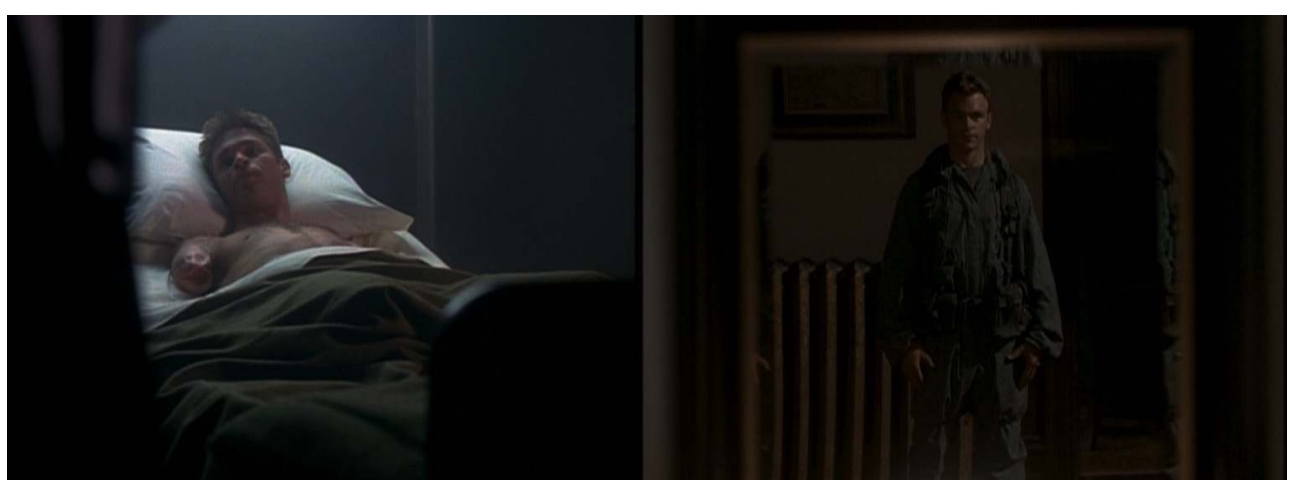

La folie qui se dégage du personnage, son insatiable besoin de vengeance et ses blessures (il est amputé des jambes et des bras) ne sont pas sans rappeler l'esthétique de Voyage au bout de l'enfer (Michael Cimino, 1978). Comme Cole et Taeger, Trimble use de dons paranormaux pour exprimer sa colère et contrecarrer l'oubli. Pour les créateurs d'X-Files, la volonté est bien de rapprocher les deux conflits, de souligner le silence des 
responsables et le désarroi des soldats. L'époque a changé, les raisons officielles du conflit ne sont pas identiques, mais les conséquences et la vérité profonde de la situation sont les mêmes. Cette forme de répétition esthétique et narrative constitue aussi une sorte de symptôme culturel. L'épisode, diffusé en 1996, ne peut s'appuyer sur une tradition cinématographique aussi importante que celle qui a suivi la guerre du Vietnam. En faisant écho à un autre conflit, la série investit un sujet qui est resté relativement ignoré des productions cinématographiques.

Dans la série, le conflit engendre les mêmes exactions et construit les mêmes personnalités. Pour preuve de ce parallèle éloquent entre deux figures centrales de la série : Walter Skinner (Mitch Pileggi) et John Doggett (Robert Patrick). Tous deux sont des vétérans blessés au combat, du Vietnam pour le premier et du Liban pour le second ${ }^{13}$. Tous les deux représentent une version positive, qui ne souhaite en rien se venger, du soldat revenu du front. Ils sont droits et objectifs, respectueux de la hiérarchie, mais surtout de leur idéal de justice. Ils figurent une forme de tempérance, tout autant qu'une perte de l'insouciance, pour ne pas dire du bonheur ${ }^{14}$. Ils indiquent ainsi une forme de continuation, parallèle à celle des anciens combattants « meurtriers ».

\section{Se chercher un ennemi (guerres majeures, guerre totale, guerres des étoiles, guerre infinie)}

Le parallélisme de traitement entre les guerres du Vietnam et d'Irak dessine une continuité entre deux sortes de conflits, en s'appuyant sur les formes réitérées que sont les figures des anciens combattants. L'armée, quant à elle, est dépeinte sous des atours sombres et violents. Elle sert des intérêts mercantiles et maquille la vérité au gré de ses objectifs les plus froids.

\section{La fin de la guerre froide n'a pas eu lieu}

Un tel détournement des fonctions de l'armée constitue une des révélations de Michael Kritschgau dans « Redux ». À ce titre, le double épisode qui ouvre la saison 5 tout autant qu'une période de doute pour Mulder quant à ses convictions sur l'existence des extraterrestres constitue une tentative marquée de réécriture de l'histoire militaire américaine depuis 1945. Phénomène relativement rare dans la série, des images d'archives, allant de la fin de la Seconde Guerre mondiale jusqu'au début des années 1990, défilent alors même que l'employeur du département de la Défense propose une véritable réinterprétation des événements (fig. 8). 
Figure 8 : La réécriture de l'Histoire militaire dans « Redux I ».

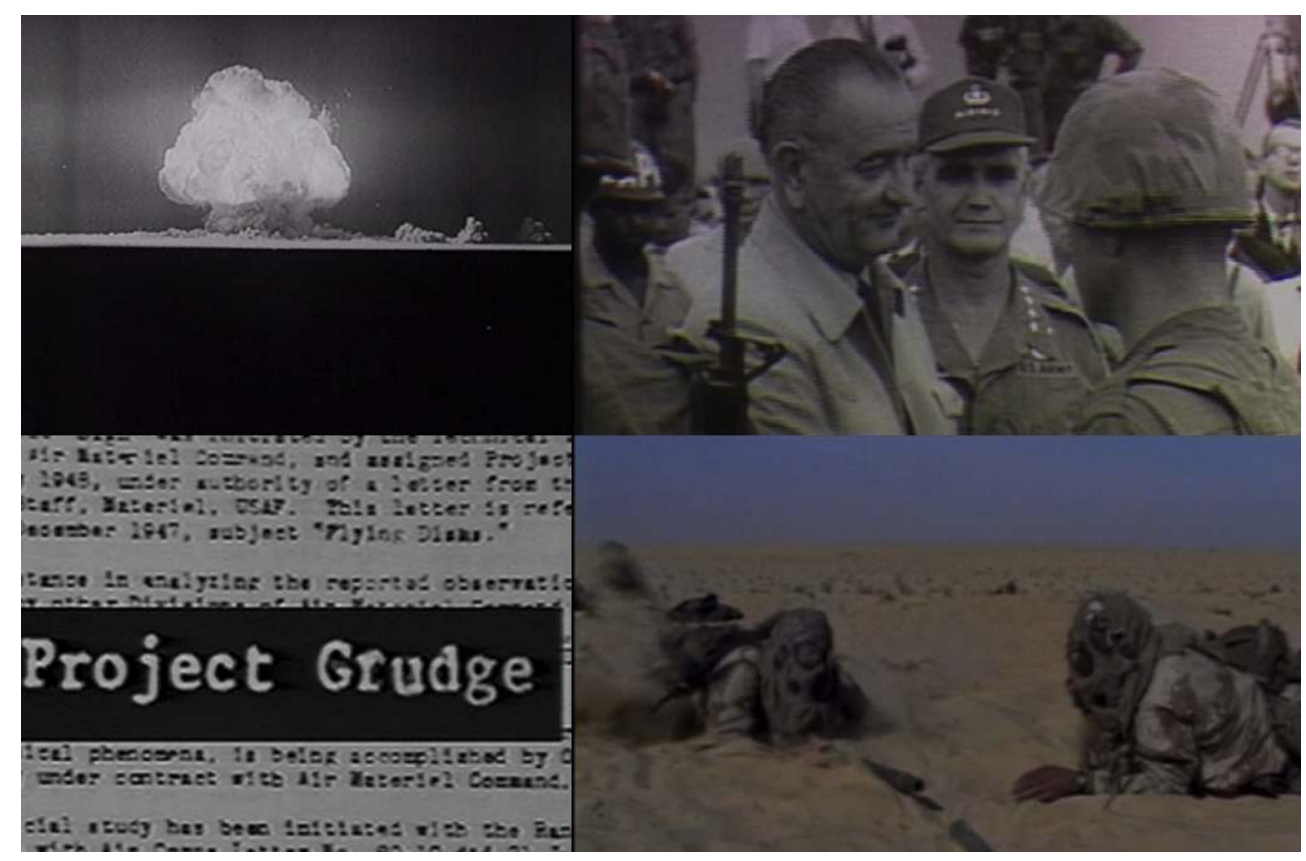

En reprenant ainsi le fil de l'Histoire des États-Unis depuis 1945, il trace les contours d'une guerre perpétuelle, entretenue par le désir impérialiste de ses différents dirigeants. Les apparitions d'OVNI qui surviennent depuis 1947 et le crash supposé à Roswell ne seraient qu'un vaste plan de mystification pour que le pays se prête à de nombreux tests technologiques et humains en toute impunité. Si les conséquences des guerres du Vietnam et du Golfe sont similaires, c'est bien parce que la situation n'a pas changé. En somme, et pour reprendre les termes de Vassily Peskow (Jan Rubes) dans « Terma » (4.9), la guerre froide n'est pas terminée ${ }^{15}$. La fin officielle d'un conflit fondé, notamment, sur la tension nucléaire, n'a rien modifié. The X-Files propose donc un récit alternatif de l'histoire des Etats-Unis, lue comme une sorte de grande guerre en mutation permanente et dont les conflits déclarés ne seraient finalement que les parties émergées.

Le Syndicat en charge du complot n'est-il d'ailleurs pas une version négative de la démocratie internationale ${ }^{16}$ en vigueur depuis 1945 ? À ce titre, les épisodes « Tunguska » (4.8) et «Terma » (4.9) constituent une sorte de condensé de la guerre moderne, de sa mutation et de sa permanence dans le monde contemporain. L'histoire débute par le démantèlement d'une cellule terroriste, dénoncée par un membre infiltré, en l'occurrence Alex Krycek (Nicholas Lea), alors ancien homme de main de l'Homme à la cigarette. Alors que Mulder est contraint de se rendre en Sibérie, il est interné dans un camp de travail, rappelant alors les heures les plus sombres de l'URSS. Après cette plongée dans l'Histoire, le récit raccroche la problématique de l'huile noire, virus extraterrestre aidant à l'invasion du monde, à des guerres économiques contemporaines centrée sur la recherche et la commercialisation des hydrocarbures (fig. 9). 
Figure 9 : Les différentes batailles dans « Terma ».

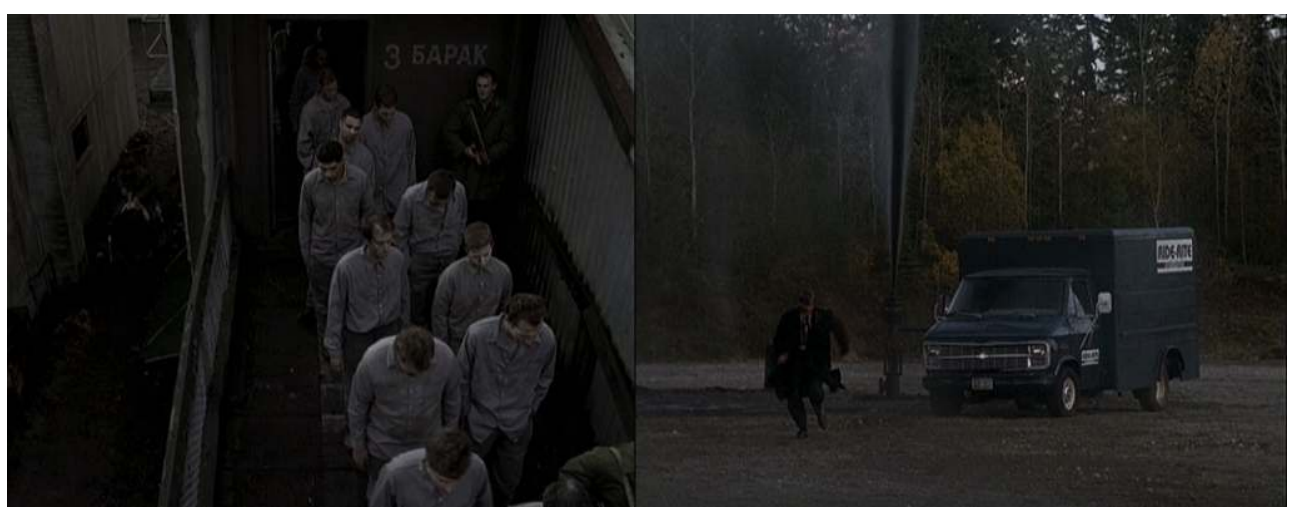

La série se pose ainsi face au monde, questionnant la fin des guerres majeures ${ }^{17}$ et mettant en scène une situation permanente de crise $^{18}$ : une guerre sans conflit ouvert.

\section{Le fantasme de la guerre des étoiles}

Avec la quatrième saison, et notamment avec le double épisode "Tunguska », l'arc mythologique d'X-Files s'internationalise. L'image des extra-terrestres vient dès lors s'inscrire dans une série d'images fantasmatiques. L'huile noire figure aussi bien le choc bactériologique, où le virus porte en lui la victoire et l'invasion, que les batailles économiques et énergétiques sur le pétrole. L'ennemi extra-terrestre est la prolongation de la projection américaine quant à l'opposant communiste ${ }^{19}$. À ce titre, arrêtons-nous quelques instants sur un épisode singulier dans le déroulement de la série, « Musings of a Cigarette Smoking Man » (4.7). Dans cet opus, les créateurs de la série prennent une nouvelle fois le parti de réécrire une partie de l'Histoire américaine, l'Homme à la cigarette étant désigné comme responsable des assassinats de John Fitzgerald Kennedy et de Martin Luther King, à chaque fois pour garantir à la forcée armée son pouvoir « obscur » sur la politique et l'opinion publique. Comme "Redux I ", l'épisode fait appel à des archives audiovisuelles mais, surtout, offre au personnage joué par William B. Davis une visage beaucoup plus humain. L'Homme à la cigarette est un militaire recruté pour ses aptitudes à respecter les ordres, délivrés pour maintenir une organisation de la société. Son action, répétée au fil des ans, pointe du doigt l'inefficience des décisions politiques et la mort de l'état de droit. Il se libère progressivement de l'autorité démocratique, pour finalement incarner un groupe autonome, placé au-dessus des lois ${ }^{20}$.

La fin de l'épisode est particulièrement représentative du besoin de cette administration d'enchaîner les conflits et, le cas échéant, de se trouver des ennemis. Alors en pleine réunion avec quelques-uns de ses collaborateurs, l'Homme à la cigarette refuse tout d'abord de répondre à l'appel téléphonique de Saddam Hussein, avant d'apprendre, hébété, la démission de Mikhail Gorbatchev (fig. 10). 
Figure 10 : le sort du monde depuis le bureau de l'Homme à la cigarette.

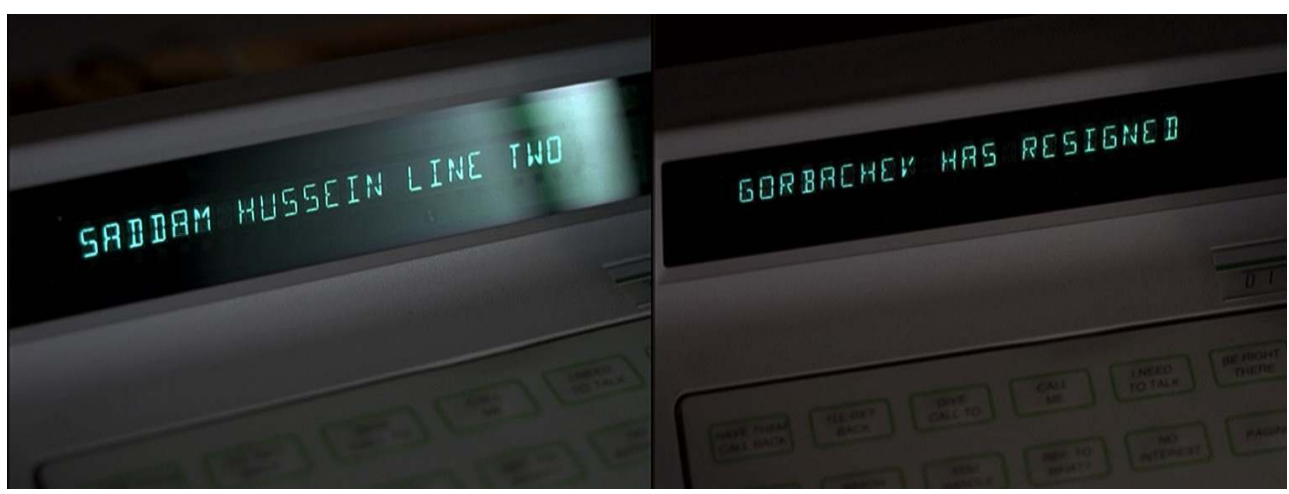

Il est par la suite contacté par Gorge Profonde pour l'aider à gérer une situation de crise : la récupération et l'exécution d'une entité biologique extra-terrestre. Alors que le conflit contre l'URSS prend définitivement fin, les deux hommes évoquent une guerre de plus grande ampleur entre la Terre et l'espace. Détournant l'habituelle opposition entre une autorité malfaisante et des hommes de terrain fondamentalement victimes, ils se présentent comme des soldats devant faire le sale boulot pour assurer l'avenir du monde. La "guerre des étoiles » est donc une fuite en avant, mêlant réalités (économiques et humaines) et fictions délirantes. Il est d'ailleurs particulièrement significatif que par cette immersion aux côtés de l'Homme à la cigarette, nous découvrions un écrivain médiocre et maudit utilisant son quotidien pour alimenter une œuvre policière dont les récits sont jugés au sens propre du terme extraordinaires. Dans ce contexte, fiction et réalité sont dangereusement imbriquées ${ }^{21}$.

Enfin, si, comme l'explique Jean Ungaro, l'extra-terrestre représente une sorte de " souillure ${ }^{22}$ » dont le peuple américain innocent se serait débarrassé, notamment par la Commission des activités anti-américaines dans les années 1950, un responsable est désigné, à savoir l'administration d'État, et plus particulièrement le ministère de la Défense qui, compte tenu de ses accointances avec le domaine économique, joue avec l'opinion publique. En somme, en développant ces images dans sa propre société, le pays s'est créé des ennemis, certains étant des infiltrés.

Le peuple est donc à la fois innocent (il ne sait pas la vérité) et coupable (il profite de ce système). Là réside un des paradoxes de la série. Tout en dénonçant une forme de mystification autour de la guerre des étoiles, elle construit son univers sur les allégories issues ou réactivées sosu la présidence de Ronald Reagan. Dans ce contexte, Mulder fait figure de héros à part, installé entre deux périodes. D'un côté, il est un homme aux valeurs résolument positives, une figure dont est même interrogée la portée messianique. De l'autre, il est une sorte d'anti-héros qui révèle la vérité aussi par le mensonge et la feinte, un sanguin qui fait de son traumatisme personnel une quête universelle, un anarchiste lui aussi infiltré au sein d'une des administrations les plus puissantes du pays.

\section{La guerre infinie : allégorie d'un discours eschatologique}

Pour une série qui n'a eu de cesse de repousser sa $f^{2}{ }^{23}$, il peut paraître paradoxal d'évoquer l'eschatologie. En effet, même si la fin du monde est présente en filigrane dans les dix saisons et est représentée dans «The Truth » (9.19), elle n'a pas eu lieu à la date annoncée (21 décembre 2012). Les créateurs ont détourné ce problème pour la diffusion 
de la dixième saison. Monica Reyes (Annabeth Gish), aujourd'hui contrainte de travailler pour l'Homme à la cigarette, explique à Scully que le processus d'infection à grande échelle a commencé à cette date (« My Struggle II », 10.6). Ce discours est surtout présent dans la dernière partie de la série, lorsque le complot prend une nouvelle forme. Avec l'arrivée des super-soldats, l'ennemi extra-terrestre prend un visage soudain très humain et se fond totalement dans la population. Si les créateurs maintiennent toujours une forme d'ambivalence entre des êtres sauveurs et des opposants destructeurs ${ }^{24}$, le militaire devient le bras armé de la destruction totale de la planète.

Ces soldats, apparus pour la première fois lors de la guerre du Golfe, apparaissent aux yeux de Zeke Josepho (Denis Forest) sous les traits des quatre cavaliers de l'Apocalypse (fig. 11).

Figure 11 : Les super-soldats, cavaliers de l'Apocalypse de « Providence » (9.10)

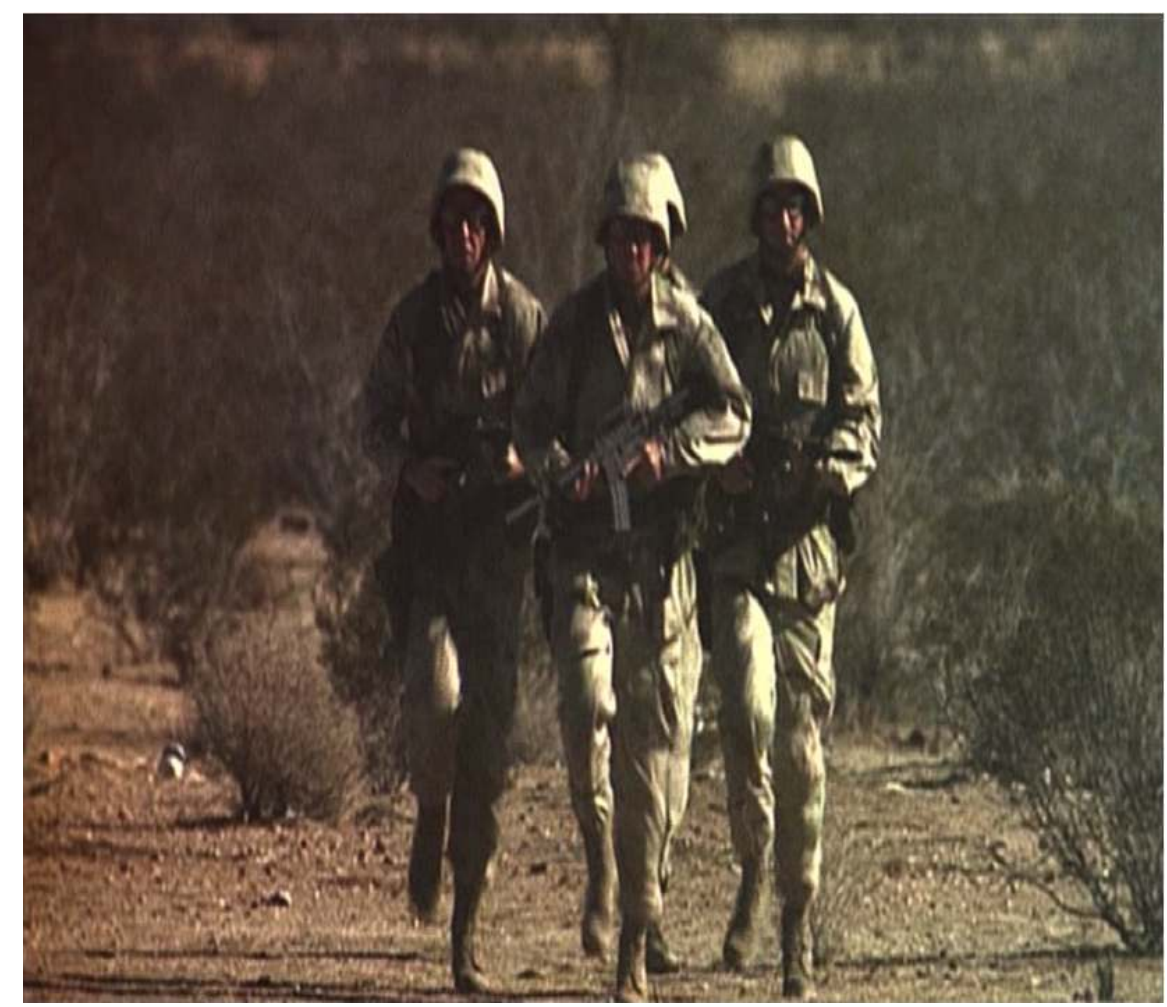

En somme, l'homme est présenté comme un loup pour l'homme. Pour les créateurs de la série, ses dérives continuelles et les guerres répétées qu'il mène ne font que se retourner contre lui. Il court à sa perte, menant un combat factice où il se combat lui-même. Tel est d'ailleurs le discours tenu par Mulder dans « My Stuggle I » (10.5) : l'état d'urgence qui va être décrété suite aux premières contaminations permettra à ceux qui ont le pouvoir de purger la planète d'une part de ses habitants, tout en faisant croire à une invasion extraterrestre.

Avec de tels propos, The X-Files revient à ses premières amours conspirationnistes, au risque, comme le souligne Scully, de servir une idéologie techno-paranoïaque isolationniste. En mêlant les avis, en opposant Mulder et Scully, la série parvient à éviter une position aussi tranchée, et par conséquent contestable. Dans sa globalité, la série tend surtout, comme nous l'avons dit plus tôt, à interroger l'impérialisme américain et la 
capacité d'un pays à se penser en sauveur du monde. Lui qui occupe une place de premier ordre dans l'échiquier mondial serait plus responsable que victime.

Dans ce contexte, The X-Files fait une nouvelle fois écho à une tradition cinématographique héritée des années 90 , qu'elle rejette cette fois en bloc. Qu'il soit foreur sur les plateformes pétrolières (Armageddon, Michael Bay, 1998), pilote de chasse ( Independence Day, Roland Emmerich, 1996) ou encore membre d'une agence secrète (Men in Black, Barry Sonnenfeld, 1997), l'Américain est présenté comme un héros en charge de résoudre une situation mondiale catastrophique. The X-Files s'écarte de ces références, marquées par le poids de la fin du millénaire, en multipliant les clins d'œil. Dans le film Fight the future (Rob Bowman, 1998), Mulder urine à la sortie d'un bar sur l'affiche du film de Roland Emmerich (fig. 12).

Figure 12 : Mulder donne son avis sur Independance day (Fight the Future, Rob Bowman, 1998)

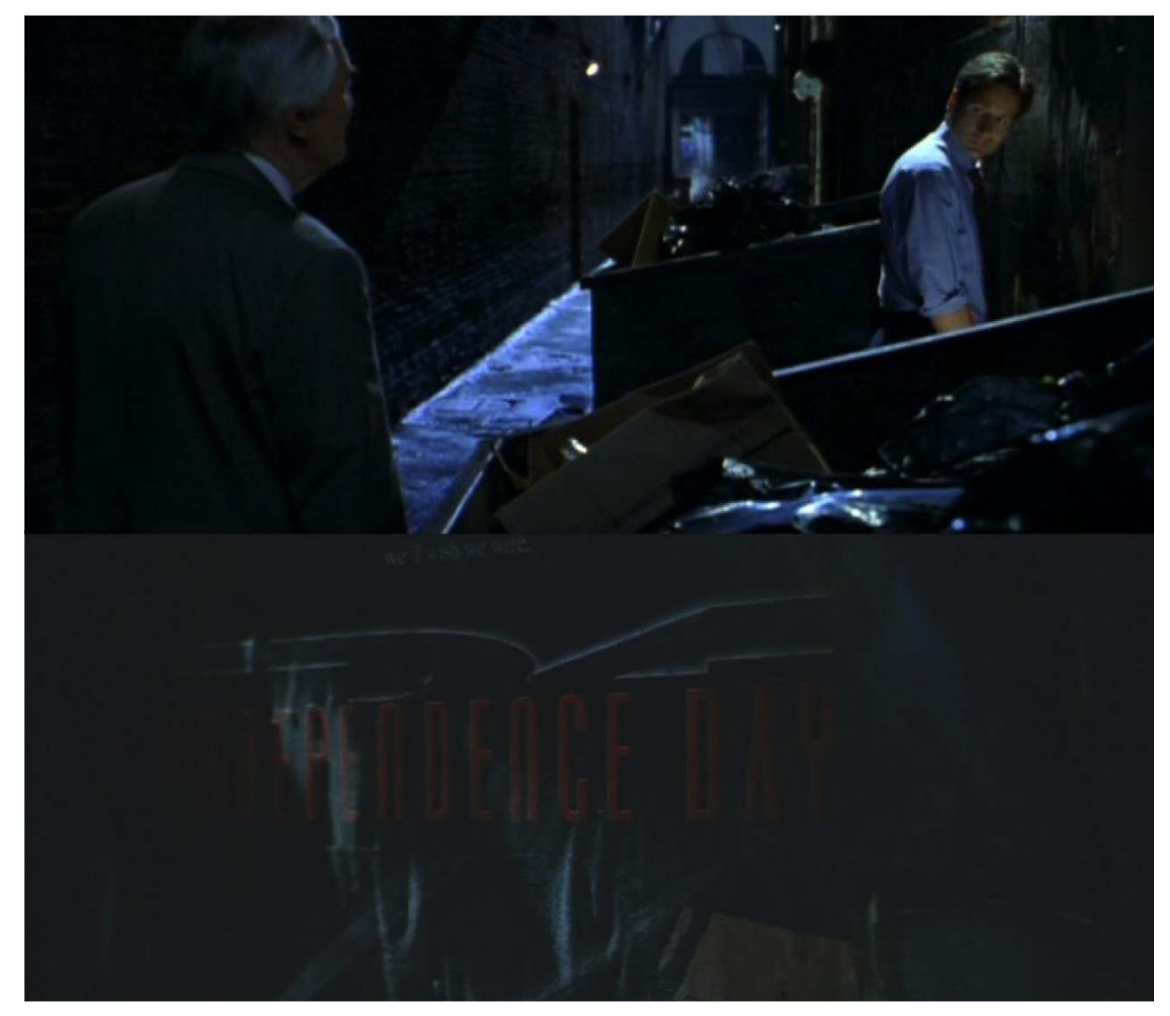

Dans « The Beginning » (6.1), Mulder explique ne jamais avoir vu Men in Black. En somme, la série maintient son discours eschatologique en repoussant des références au cinéma catastrophe, en vogue dans la seconde moitié des années 90 , portant un regard beaucoup plus sombre et fustigeant la position de l'État américain.

\section{La morale de l'Histoire : le combat intellectuel d'X-Files}

31 Nous avons pu constater en quoi la série se place en dénonciatrice de pratiques mémorielles en vigueur à son époque. À sa manière, elle délivre une bataille critique, donnant une dimension intellectuelle au format télévisuel. Lors de son retour en 2016, la série se raccroche au cadre ultra-contemporain, en faisant notamment référence à la guerre contre la terreur et à l'affaire Snowden, le 11 septembre étant pour Chris Carter et son équipe un phénomène de l'ordre de la persistance ${ }^{25}$, en même temps qu'un sujet 
d'interrogation sur la responsabilité et le statut des images ${ }^{26}$. Cette posture révèle une volonté de transparence des créateurs et inscrit The X-Files dans une époque en mutation.

\section{La ruse contre la force}

Mulder et Scully sont deux agents en quête permanente de preuves. Touchés par un doute quasi-méthodologique, notamment en ce qui concerne la seconde, médecin de formation, ils tentent pendant dix saisons de confondre les responsables du Complot. Face aux méthodes occultes, ils essayent tant bien que mal de « faire toute la lumière ». Dans cette démarche, la connaissance du folklore et des mythes, de la psychologie (Mulder) et des sciences (Scully) apparaissent comme les marques d'une intelligence en marche. Isolés, ils opposent la ruse ${ }^{27}$ à la force des pouvoirs en place, inamovibles et puissants, pour imposer une idée de la modernité contre l'archaïsme guerrier ${ }^{28}$. À de nombreuses reprises, Mulder et Scully feignent des défaites pour mieux remporter des batailles, usant à leur manière de dissimulation et de tromperie.

Mulder, par exemple, simule un suicide («Redux I», 5.1), tandis que Scully décide de garder une partie des affaires non-classées dans son appartement (« Nothing Important Happened Today ", 9.1). Mulder explique, au cours de son procès, comment il a réussi pendant neuf ans à avancer caché. En somme, il propose une forme intuitive de combat face à la force stratégique imaginée par les tenants du Complot, mais représentée aussi par des personnages positifs tels que Skinner ou Doggett. La ruse permet non seulement de gagner des batailles, notamment parce qu'elle permet de surprendre l'ennemi, mais aussi de le confondre, c'est-à-dire à le mettre face à sa vérité, dans une dimension ici juridique, éthique et morale. Tel est le sens du simulacre de tribunal face auquel Mulder doit se présenter dans «The Truth » (9.19) : si le procès est perdu, c'est bien parce que les responsables ne sont pas en mesure d'assumer leurs exactions. En somme, la victoire, au même titre que la vérité, se situe sur un autre terrain.

Dans ce contexte, le grand ennemi de Mulder et Scully, l'Homme à la cigarette, fait figure de stratège complet. En effet, si les deux agents font appel à la ruse, c'est aussi pour compenser un déficit de force. De son côté, l'Homme à la cigarette l'utilise à loisir. Il fait alors figure de prince-stratège si cher à Machiavel. Mais nous ne sommes pas dans un schéma rappelant la bataille opposant David contre Goliath. Mulder, au fur et à mesure des saisons, apprend à faire confiance et évite ainsi la posture de l'anarchiste radical en guerre contre le reste du monde.

\section{2. The X-Files contre le « Fox Factor».}

35 La saison 10 est l'occasion d'intégrer un nouveau personnage d'importance dans la narration d'X-Files: Tad O'Malley (Joel McHale). C'est lui qui permet à Mulder et Scully de reprendre du service et de rouvrir les affaires non-classées. Il est le présentateur vedette une émission diffusée sur Internet, "Squad», chargée de dénoncer les dérives et les complots de l'état américain. Les deux héros doutent d'abord de sa probité, Mulder se prêtant à une comparaison peu flatteuse avec Bill o'Reilly, présentateur sur Fox News de The O'Reilly Factor ${ }^{29}$. La série tente alors de prendre position dans le traitement médiatique de la guerre, notamment les conflits en Afghanistan et en Irak. À coté des quelques images d'archives, la série fait cette fois intervenir de fausses images de médias, 
dénonçant le caractère factice de l'information sur la guerre. En somme, elle prend position contre les pratiques de Fox News et contre leurs effets potentiels.

L'effet Fox (Fox Factor) peut être défini comme la collusion entre un gouvernement et un média (aligné et engagé) afin de créer en direct (live) de la propagande et du patriotisme dans l'opinion publique par le biais de la peur (fear factor). En retour, l'opinion conforte le gouvernement dans ses actions et lui laisse les mains libres, surtout en ce qui concerne la politique extérieure du pays. Ce processus est efficace, car il court-circuite les instances légitimes les plus larges $\mathrm{du}$ parlementarisme et de la représentation nationale; il renforce l'exécutif et le protège des réflexes démocratiques profonds de la population américaine (pluralisme, noningérence). L'unilatéralisme des États-Unis depuis le 11 septembre 2001 peut en partie s'expliquer par cet effet (antérieur à la guerre, perceptible dès les élections présidentielles très contestées de novembre 2000). ${ }^{30}$

Il pourrait paraitre paradoxal que The X-Files s'exprime en opposition au groupe de télévision qui le diffuse depuis des années. Mais entre libéralisme démocrate et une vraie forme de conservatisme, la série n'a jamais été à une contradiction près, imposant dès le début des années 90 son indépendance face à la Fox ${ }^{31}$. La série se situe donc plus volontairement du côté de l'effet $\mathrm{CNN}$, "processus » de "surveillance en direct» en mesure d'influencer la "politique extérieure des États-Unis », notamment en défendant l'idée d'une "prise de conscience de l'opinion qui, en retour, fait pression sur ses dirigeants $\aleph^{32}$. Elle exhorte surtout ses téléspectateurs à éviter tout suivisme et tout patriotisme béat.

\subsection{La quête de transparence}

The X-Files s'est toujours appuyé sur un fonctionnement dialectique. Entre l'homme et la femme, entre l'intuitif et la scientifique, entre la postmodernité et la modernité, entre le Bien et le Mal, entre la vérité et le mensonge, elle tente, par une narration complexe, de faire ressortir un raisonnement et une interprétation générale du monde. Il n'est donc pas étonnant de constater que, du côté de l'armée, nous retrouvions aussi bien des victimes que des responsables. Cette narration est accentuée par la position particulière des deux agents, des enquêteurs relativement vierges du pouvoir délivrés par le fait de savoir. En somme, Mulder et Scully ne tirent pas les ficelles: ils sont avant tout les spectateurs du spectacle du monde. Ils n'ont pas été pervertis, au contraire de ceux qui possèdent la vérité (et qui sont donc en capacité de l'occulter). Nous rattachons naturellement des indicateurs positifs à la quête de Mulder et Scully. Ils veulent dévoiler pour comprendre, connaître et progresser, mais aussi pour éviter tout fatalisme. Il s'avère toutefois que la réalité est plus complexe, comme le prouvent les hésitations de Mulder dans « The Truth» (9.19), la connaissance faisant de lui un être responsable.

\section{Conclusion}

La série, portée du côté de la dénonciation et de la morale, avoue en fin de parcours la difficulté d'un achèvement. La guerre intellectuelle et métaphysique menée pendant de longues années ne permet pas un réel happy end ${ }^{33}$, où le Bien aurait finalement triomphé. À ce titre, la série se situe dans une période de changement, la morale étant entachée 
d'une dimension dramatique et dépressive. The X-Files est finalement symptomatique d'une époque et devient, en ce sens, charnière dans l'histoire des séries télévisées. Nous sommes en effet bien loin du " moralisme reaganien ${ }^{34}$ » des séries des années 80 , la série se situant du côté de la complexité et de la modernité artistique. Déjà torturés, ses héros ne sont à l'inverse pas encore les personnages plus sombres d'Homeland (Showtime, 2011-) ou de 24 (Fox, 2001-2014). Ils sont à la recherche d'un rapport phénoménologique à la vérité et sont encore très éloignés de l'anti-héros présent à partir du milieu des années 2000 dans des séries telles que Dexter (Sowtime, 2006-2013) ou encore Breaking Bad (AMC, 2008-2013) $)^{35}$. S'appuyant sur un couple héroïque porté par des valeurs ${ }^{36}$, le récit construit une théorie d'une vérité qui se cache dans les êtres ${ }^{37}$. La série devient alors symptomatique d'une idéologie qui vient agir comme une "consolation à la perte définitive de la transparence dans nos sociétés démocratiques ${ }^{38}$ ». Mais les créateurs de The X-Files ne pensent pas que cette recherche est une quête vaine. C'est un combat lui aussi perpétuel qu'ils mènent, un combat au cours duquel la série joue le rôle de gardefou intellectuel et moral, notamment dans les périodes de dérives sécuritaires. Elle s'affirme, en somme, comme un lanceur d'alertes fictionnelles.

\section{BIBLIOGRAPHIE}

ColonNA Vincent, L'art des séries, 1. L'appel du happy end, Paris, Payot, 2010.

CoLonNA Vincent, L'art des séries, 2. L'adieu à la morale, Paris, Payot, 2015.

ESQUENAZI Jean-Pierre, Mythologie des séries télévisées, Paris, Le Cavalier bleu, « Mytho ! », 2009

FRAU-MEIGS Divina, «L'effet Fox contre l'effet CNN : le journalisme américain entre surveillance et propagande », in Jean-Marie Charon et Arnaud Mercier (sous la dir. de), Armes de communication massive. Informations de guerre en Irak: 1991-2003, Paris, CNRS Éditions, 2004.

GAI Frédéric, « The X-Files (1993-2002) ou le jeu des niveaux narratifs », in TV/Series [En ligne], 7 (2015), « Le pilote et la chute », http://tvseries.revues.org/280 (dernière consultation le 26 octobre 2016).

HOLEINDRE Jean-Vincent et Frédéric Ramel (éds.), La Fin des guerres majeures, Paris, Economica, «Sratégies et doctrines », 2010.

JOST François, De quoi les séries américaines sont-elles le symptôme?, Paris, CNRS, 2011.

KREIDER S. Evan, « Walter Skinner. The X-Files' unsung hero », in Dean A. Kowalski (éd.), The Philosophy of the X-Files, Lexington, The University Press of Kentucky, « The Philosophy of popular culture », 2009.

MOLIA François-Xavier, «Blockbusters et mauvaise conscience : représenter la catastrophe après le 11-septembre », in David Lescot et Laurent Veray, Les mises en scènes de la guerre au XXe siècle. Théâtre et cinéma, Paris, Nouveau monde éditions, « Culture-médias », 2011.

REBEIHI Ali, avec Marjolaine Boutet, Ariane Hudelet, Thibaut de Saint-Maurice et Pierre Sérisier, « Les séries télé nous donnent-elles des leçons de vie amorales? », Ça va pas la tête !, [En ligne], 
https://www.franceinter.fr/emissions/ca-va-pas-la-tete/ca-va-pas-la-tete-05-aout-2016

(dernière consultation le 26 octobre 2016).

RENARD Jean-Bruno, «L'homme sauvage et l'extraterrestre », in Diogène, $\mathrm{n}^{\circ}$ 127, juillet-septembre 1984, p. $70-88$.

RENARD Jean-Bruno, «Extraterrestres », in Dictionnaire des mythes d'aujourd'hui, sous la dir. de Philippe Brunel, Monaco, Éditions du Rocher, 1999, p. 267-275.

STORA Benjamin, Imaginaires de guerres. Algérie, Viêt-Nam, en France et aux États-Unis, Paris, La Découverte, 1997.

UNGARO Jean, Américains héros de cinéma, Paris, L’Harmattan, « De visu », 2005.

\section{NOTES}

1. Nous faisons ici référence au second film, I Want to believe, sorti dans les salles en 2008.

2. Les premières annonces autour d'un revival et le format resserré de la série ont amené certaines communautés de fans à considérer cette reprise comme une minisérie. Le fait que cette saison 10 s'inscrivent clairement dans la continuité des précédentes nous incite toutefois à favoriser une analyse sérielle plus traditionnelle.

3. Nous avons déjà mentionné Mount Weather, site de repli pour le gouvernement américain en cas de catastrophe majeure. George W. Bush s'y était d'ailleurs replié le 11 septembre 2001. Notons qu'elle est notamment occupée par la Federal Emergency Management Agency (FEMA), une des cibles privilégiées de la série. Nous pourrions aussi évoquer le cas de The Lone Gunmen (2001), spin-off de la série centré sur les trois hackers accompagnant Mulder et Scully pendant neuf saisons. Le premier épisode, diffusé le 4 mars 2001, met en scène un avion venant s'écraser dans l'une des tours du World Trade Center. Comme souvent dans la sphère d'X-Files, les responsables sont les dirigeants américains, qui tentent par là de relancer l'industrie de l'armement.

4. Benjamin Stora, Imaginaires de guerres. Algérie, Viêt-Nam, en France et aux États-Unis, Paris, La Découverte, 1997, p. 244.

5. En 1972, le colonel des Forces Spéciales américaines James Braddock (Chuck Norris) est retenu dans un camp de prisonniers vietnamien. Après s'être évadé de ce camp et être rentré aux USA, il se voit confier la mission de localiser et de sauver un groupe d'hommes portés disparus.

6. En 1987, le Pentagone estime à 2273 le nombre de soldats dont la trace n'a pas été retrouvée. Parmi eux, 1172 sont catalogués comme Missing in Action (MIA). Le sujet devient polémique en 1990, alors qu'une photo venant d'Asie et datée du 25 avril montre trois hommes d'une soixantaine d'années, identifiés par les familles respectives comme trois MIA.

7. Stora, op. cit., p. 219.

8. Remarquons que les créateurs de la série la lient à la tradition du cinéma de genre en convoquant Tony Todd pour incarner le " prêcheur » Augustus Cole, l'acteur étant surtout connu pour son interprétation de Candyman (Bernard Rose, 1992).

9. «La représentation des événements a largement dominé la présentation des faits, véritablement 'réprimés'. Ce nouveau 'langage' visuel, loin d'éclairer sur les enjeux profonds du conflit en cours, s'ingénie plutôt à retarder la lente édification d'une raison critique. Il contribue à renforcer la confusion entre monde réel et image : l'évident, c'est le visible. Sous prétexte de 'vérité, le visuel fonctionne comme opération de destruction mentale. La caméra sert moins à produire des images, avec volonté-mimer d'une réalité sensible, qu'à falsifier les dimensions réelles, géographiques ", Stora, op. cit., p. 129-130.

10. Ibid., p. 130. 
11. Il nous semble tout à fait significatif que Peter LaCroix joue deux vétérans, l'un du Vietnam (« Unrequited ») et l'autre de la guerre du Golfe.

12. Nous empruntons ici le titre français de l'épisode.

13. Le passé vietnamien de Skinner est évoqué à plusieurs reprises tout au long de la série. L'histoire militaire de Doggett devient rapidement centrale, au gré de ses contacts avec ses anciens compagnons d'armes Knowle Rohrer («Per manum », 8 .13) ou Shannon C. McMahon (« Nothing Important Happened Today », 9.1-2).

14. Sur ce sujet voir l'article de S. Evan Kreider, « Walter Skinner. The X-Files' unsung hero », éd. Dean A. Kowalski, The Philosophy of the X-Files, Lexington, The University Press of Kentucky, «The Philosophy of popular culture ", 2009, p. 159-175.

15. Il est important de noter qu'avec ce double épisode, les créateurs donnent une dimension internationale à leur récit et sortent du territoire national.

16. L'ONU est représenté de manière très ambiguë au travers du personnage de Marita Covarrubias (Laurie Holden). Si elle est bien une informatrice pour Mulder, venant s'inscrire à la suite de Gorge Profonde (Jerry Hardin) de Monsieur X (Steven Williams), lui faisant profiter de son aide précieuse, notamment pour obtenir un visa ("Tunguska », 4.8), elle s'avère rapidement être un des membres du Syndicat, tout en suivant sa propre voie («Patient X» 5.13).

17. Frédéric Ramel et Jean-Vincent Holeindre apportent l'éclairage suivant sur la notion de guerres majeures : « Même si les définitions varient selon les auteurs, trois éléments doivent être réunis pour qu'on puisse parler de guerre majeure : le conflit est engagé par deux ou plusieurs armées organisées sous l'autorité d'Etats; l'affrontement est marqué par un choc des technologies, qui reflète la puissance industrielle des belligérants; la guerre s'achève par des victoires tactiques et stratégiques traduites en issues politiques", "Penser les guerres majeures ", éd. Jean-Vincent Holeindre et Frédéric Ramel, La Fin des guerres majeures, Paris, Economica, "Sratégies et doctrines", 2010, p. 1-13, p.1. La fin de ces guerres majeures entraîneraient selon les auteurs vers une nouvelle forme de conflit, marquée par une absence d'affrontements armés, par une conquête des cœurs et, surtout, par l'idée d'une guerre sans fin.

18. Réfléchissant sur la situation guerrière à notre époque, Jean Dufourcq constate qu'à «l'opposé des bella, ces grandes guerres classiques ordonnées par les intérêts et polarisées par les idéologies, c'est la guerra qui se développe dans les crises, soir sous la forme d'une guérilla cruelle, multiforme, globale contre les valeurs et les systèmes que véhicule une certaine forme d'ordre libéral occidental, soit sous la forme de transformations imposées et déblocages brutaux de sociétés immobilisées ; avatar nihiliste et barbare d'un côté, avatar illégal de l'autre, de ce qui était devenu un art pour gens civilisés ou presque, la nouvelle guerra est totale dans son essence même ", « Penser la guerre au XXI siècle : des combats sans guerre ? », Ibid., p. 64-79, p. 73.

19. «En revanche elle n'est pas nouvelle chez les Américains : la menace des extra-terrestres, qui exorcisait la crainte du communisme et les peurs liées à la guerre froide, la crise de la vache folle et la perte de confiance en les politiques qui nous cachent des choses ont servi de 'bain d'immersion' aux récits d'X-Files", François Jost, De quoi les séries américaines sont-elles le symptôme?, Paris, CNRS, 2011, p. 12.

20. La modification du Syndicat, structure émanant du département de la Défense en organe privé indépendant vers 1973 (faisant ainsi référence au scandale du Watergate), est largement traitée dans «Two fathers" (6.11) et "One son» (6.12), épisodes au cours desquels le premier complot prend fin.

21. Cette confusion est soulignée par le titre de la seule publication acceptant un de ses textes, Roman a Clef.

22. Jean Ungaro, Américains héros de cinéma, Paris, L'Harmattan, « De visu », 2005, p. 28.

23. Sur ce sujet, voir Frédéric Gai, "The X-Files (1993-2002) ou le jeu des niveaux narratifs », in TV/Series [En ligne], 7 (2015), «Le pilote et la chute », http://tvseries.revues.org/280 (dernière consultation le 26 octobre 2016). 
24. Cette ambivalence est intrinsèque à l'image des extra-terrestres dans la culture folklorique, mais aussi dans la fiction. Voir sur ce sujet Jean-Bruno Renard, «L'homme sauvage et l'extraterrestre ", in Diogène, $\mathrm{n}^{\circ} 127$, juillet-septembre 1984, p. $70-88$ et Jean-Bruno Renard, «Extraterrestres », in Dictionnaire des mythes d'aujourd'hui, éd. Philippe Brunel, Monaco, Éditions du Rocher, 1999, p. 267-275.

25. Sur ce sujet, voir notamment François Jost, op. cit., p. 11.

26. Sur ce sujet, voir l'article de François-Xavier Molia, «Blockbusters et mauvaise conscience : représenter la catastrophe après le 11-septembre ", in David Lescot et Laurent Veray, Les mises en scènes de la guerre au XXe siècle. Théâtre et cinéma, Paris, Nouveau monde éditions, "Culturemédias ", 2011.

27. N'oublions pas que le prénom de Mulder, Fox, fait autant référence au diffuseur de la série qu'au renard, animal rusé par excellence.

28. Sur ce sujet, voir l'article de Jean-Vincent Holeindre, « La ruse et les formes contemporaines de la guerre ", in La Fin des guerres majeures, op. cit., p. 47-63.

29. Polémiste de la droite américaine, Bill O'Reilly se positionne ouvertement comme extrêmement conservateur sur la plupart des sujets qu'il aborde, que ce soit à propos de l'avortement, du mariage entre personnes de même sexe, de la religion et de la guerre en Afghanistan et en Irak.

30. Divina Frau-Meigs, "L'effet Fox contre l'effet CNN: le journalisme américain entre surveillance et propagande ", éd. Jean-Marie Charon et Arnaud Mercier, Armes de communication massive. Informations de guerre en Irak : 1991-2003, Paris, CNRS Éditions, 2004, p. 188-189.

31. «Faire accepter par le plus petit des grands réseaux américains un projet comme X-Files : Aux frontières $d u$ réel était une gageur difficile. Spécialisé dans le genre comique, pas toujours d'excellent ton, le réseau Fox a l'habitude de commander de multiples pilotes sans jamais se décider à prendre une série, surtout pas fantastique : les séries de science-fiction ou étranges ne sont plus guère à la mode. Mais Chris Cartier (...) tient à son projet (...). Carter ne fait aucune concession pour convaincre plus facilement le réseau ", Jean-Pierre Esquenazi, Mythologie des séries télévisées, Paris, Le Cavalier bleu, « Mytho ! », 2009, p. 28.

32. Divina Frau-Meigs, op. cit., p. 188.

33. Sur ce sujet, voir les deux ouvrages de Vincent Colonna : L'art des séries, 1. L'appel du happy end, Paris, Payot, 2010 et L'art des séries, 2. L'adieu à la morale, Paris, Payot, 2015.

34. Sur ce sujet, voir Marjolaine Boutet, « Histoire des séries télévisées », éd. Sarah Sepulchre, Décoder les séries télévisées, Bruxelles, De Boeck, «Infos \& Com », 2011, p. 36.

35. Sur ce sujet, voir l'émission du 5 août 2016 de Ça va pas la tête!, « Les séries télé nous donnentelles des leçons de vie amorales? » [En ligne], https://www.franceinter.fr/emissions/ca-va-pasla-tete/ca-va-pas-la-tete-05-aout-2016 (dernière consultation le 26 octobre 2016).

36. Nous nous appuyons sur la classification des modes fictionnels de Northrop Frye repris par François Jost, op. cit., p. 18-19.

37. Ibid., p. 43-49.

38. Ibid., p. 62. 


\section{RÉSUMÉS}

Au milieu de la pléiade de sujets abordés par The X-Files, la guerre occupe une place particulière. Présente aussi bien dans les épisodes « fermés ", qui font écho à la tradition du film de genre, que dans l'arc mythologique, elle présente de prime abord une distinction fondamentale entre le soldat, première victime des conflits, et l'armée, structure participant de l'occultation des exactions commises par les États-Unis depuis 1945. Auprès de l'ancien combattant, le téléspectateur pénètre dans l'irréel des guerres du Vietnam et d'Irak, ainsi que dans la violence sensible imposée par les décisions politiques successives. Pointant du doigt la responsabilité de l'armée américaine dans le cadre géopolitique contemporain, elle remet en doute les discours officiels pour mieux constater la position impérialiste américaine, qui entretient un état guerrier permanent pour servir des intérêts militaro-industriels. Si les « guerres majeures » ont pris fin, l'Amérique maintient la possibilité d'avoir des ennemis dans un cadre de mystification hérité des années de Guerre froide. De son côté, la série formule un discours dramatique sur les dérives humaines et sur la fin du monde, faisant quant à elle de l'arme fictive une manière d'alerte, pour mieux contrecarrer le traitement médiatique de la guerre et proposer une forme de critique renouvelée tout au long de plus de deux décennies de diffusion.

Among the plethora of topics covered by The X-Files, war has a special place. Present in both the "closed" episodes that echo the tradition of genre films, as in the mythological arc, it presents at first a fundamental distinction between the soldier, the first victim of conflicts, and the army, a structure involved in the occultation of abuses committed by the United States since 1945. Beside the veteran, the televiewer enters the unreal wars in Vietnam and Iraq, as well as the sensitive violence imposed by successive political decisions. Pointing the responsibility of the US army in the contemporary geopolitical context, it calls into question the official speeches to better see the US imperialist position, which maintains a permanent war state to serve military and industrial interests. If "major wars" ended, United States maintains the possibility to have enemies in a mystification framework built during the Cold War. For its part, the series offers a dramatic speech on human excesses and on the end of the world, making the fictional weapon a way to alert and criticize, to better counteract the media's treatment of war and to propose a renewed criticism form throughout more than two decades of broadcast.

\section{INDEX}

Mots-clés : X-Files : Aux frontières du réel, guerre, guerre froide, guerre du Vietnam, guerre du Golfe, 11 septembre, science-fiction

Keywords : X-Files (The), war, Cold War, Vietnam War, Gulf War, 9/11 


\section{AUTEUR}

\section{FRÉDÉRIC GAI}

Frédéric Gai est en contrat post-doctoral au LASLAR de Caen Normandie dans le cadre de l'ANR «LiTTéPUB ». Spécialiste de l'histoire du livre et de l'édition, il travaille aussi sur la littérature sportive et poursuit ses recherches sur l'œuvre de François Mauriac. Il rédige actuellement un ouvrage sur The X-Files.

Frédéric Gai is a post-doctoral fellow in the LASLAR at the University of Caen Normandy, working within the ANR « LiTTéPUB ». He's a specialist of books and publishing history, and he also works on sports literature. He is still carrying on researches on the work of François Mauriac. He is also currently writing a book on The X-Files. 